\title{
The Role of Rural Decentralized Religion in the Rural Governance
}

$$
\text { Ting } \mathrm{Li}^{1, \mathrm{a}^{*}} \text {, Siling Liao }{ }^{1, \mathrm{~b}} \text { and Weiwei Peng }{ }^{1, \mathrm{c}}
$$

${ }^{1}$ North China Electric Power University Institute of Humanities and Social Science, Beijing, China

aLitng2016hy@163.com; liaosiling2016hy@163.com;'pengweiwei2016hy@163.com

*The corresponding author

Keywords: Rural decentralized religious; Collective action; Grassroots selfgovernment

\begin{abstract}
The decentralized rural religion in China's development for a long time, on to ancient times, to the contemporary society, decentralized religious beliefs play an immeasurable role in the process of the development of rural. This article takes the the Guangxi Zhuang Autonomous Region $\mathrm{g}$ Lvluo village as an example, analyzes the influence of the rural scattered religion on the collective action, and it will be applied to the management of the rural grassroots self-government.
\end{abstract}

\section{Introduction}

The Decentralized Religion. The concept of "the decentralized religion" was presented by C.K. Yang Professor .The concept originated in the Weber and Granet, then mastered into C.K. Yang finally [1]. C.K. Yang proposed" the decentralized religion" which is different from" institutional religion ", is refers to the religious organizations and internal organization system is not yet institutionalized, its concept and ritual is the concentrated reflection of the secular social system generally. Religion in China built on the faith of God, the soul, the ritual and organization, blood as a link to contact, mostly without clear constitution and system of doctrine, but self-contained., which handed down by word of mouth and worship ceremonies, it is a typical representative of the dispersion of religion.

Chinese farmers live in the patriarchal clan society which look the family as the center point, ritual, visits and other traditional activities were led by the parents in the village, chief of the fathers, at the same time, the villagers has undisputable admiration for ancestors, and these two kinds of emotion and the traditional Confucian notion mixed, that turn into the decentralized Rural Religion. The local nature and historical performance make the decentralized Rural Religion accepted by the villagers easily, the village elders follow the tradition and the dispersed the rules of religious, under the influence of the family newborn children often accept these tradition notions changed from passive to fulfill conscientiously. Farmers' sickness, death ,weddings, funerals and other important custom of rituals and religious activities, all that build a strong religious culture atmosphere. The cultural concepts reflected by these kinds of cultural forms, cultural concept always tend to be concentrated in the folk religious belief, that sound and penetrating into people's thought concept, which provides the social and cultural foundation.to accept region notion. [2]The author believes that with the urbanizetion of the rural population clan ties and folk contact will become an important basis of public governance in rural areas, rely solely on autonomous mass organizations at the grass-roots level may cannot solve the supply problem of rural public goods and services commendadly, which should be supplemented by dispersing religious concept to lead to way.

\section{Decentralized the Role of Religion in Rural Governance-based on the Analysis of Yulin City Bobai County of Guangxi Zhuang Autonomous Region, the Lvluo Village}

The research of religion in Yulin city, Guangxi zhuang autonomous region, Bobai dispersivity of the Lvluo village has strong representative. This article will use this example to analyze the dispersity of rural collective action generated by the actual utility of the decentralized rural religion:

Under the planned economy era, the Lvluo village enjoyed "Commons", and many production and living activities arranged by village cadres group. After the reform and opening-up policy, 
freedom of religious belief was back, thus, rural masses who was previously forced to give up religious belief, again go into the temple, and restart the decentralized religious life. With the development of market economy, the social dominant spirit lost, and social lose standardize which guide the focal point of thought and behavior. People's hearts were no refuge, in confusion, and social group is in the midst of anomie, discrete position. ${ }^{[3]}$ At this point, the decentralized religious belief has been gradually picked up, and become the main idea in the process of rural modernization drive to maintain ties.

Thought Polymerization. Lvluo village, decentralized of religious belief has no formal rules and regulations, but it can become the whole village collective beliefs. Even if the knowledge level is higher, young people do not have a strong sense of identity to it, and they will complete all forms of respect or obey the demands of the family. Decentralized rural religion in the village has become the default local rules, and people who are not to do things by faith "hidden rules" of will be blamed. A middle-aged woman said: "Everyone in the village will talk about together of someone who does something good that is blessed. Who did not go to the ancestral temple to worship our ancestors, the villagers would blame them too." The villagers have the same beliefs among them, maybe with forced power, but basically realize the rural collective action of the mind, which is the most fundamental utility of decentralized religion to promote rural collective action.

Sharing the Economic Achievements. Lvluo village has a cleric called "sun" people long ago already built the temple for the "sun" through raising money. fortune-telling, praying for the village people. Most of the people in our village get sick, have a disaster or in major holiday will bow down to the cleric. In recent years villagers donate money to rebuild he shabby temple. Such decentralized religious financing way in the countryside has an irreplaceable role in economic development. For example, to build cement road in the village, is dominated by the rich people in the village, and all households pay for it. The rich naturally donate more and poor people do their best. Also, the Lvluo village school construction has taken such financing way. Some rich people play a leading role in all sorts of collective action through the decentralized of religion, providing a lot of money for village construction, and the whole village Shared the interests, which greatly reduce the poor psychological "hatred". The system of rural villagers through decentralized religious model to provide all kinds of public goods makes the village share economic development together, reducing the gap between the rich and the poor.

The Common Cultural Activities. Lvluo village, formed recreational activities generation to generation in the course of decentralized religion: in the Spring Festival, the villagers make a vow to the "sun" temple shakily, whether the will become true or not, all need to go back. In addition, the whole village goes to the ancestral worship ancestors, and children must go with men, but women can stay home, which strongly reflected the ideas of continuation. Place food in turn in the ancestral temple from house to house, line three big bow and pray, and then set off firecrackers, which is an expression of celebration of the New Year. Another activity is the lion dance, and villagers hang red envelope with a bamboo pole, with small oranges, then lions spiting picked the red envelope. The money in the envelope is decided by their own, but must give, because the lion dance is a collective recreational activities, in accordance with the village belief, the customs cannot cancel, so all should pitch in, and give the workers hard rehearsals for their services.

In the process of urbanization, many farmers go to city for development. The contact of rural population is weak, and decentralized of religious belief for emotional contact highlights: In tomb-sweeping day, many people returning from cities collectively to rural mountain to worship ancestor. Then villagers kill pigs, have dinner and chat with each other, which strengthened the connection between the village people. Looking at Lvluo village in recent years, some people find that the village lacks of common activities, and the heads began to set up an activity center, financing, planning, and successfully established a table tennis room, chess and card room, basketball court, etc. All of these are the collective actions of villagers based on decentralized religious ideology and achieve a small range of self-governance.

People Help Each Other in Natural and Man-made Disasters. Most of Lvluo villagers followed such beliefs: one good turn deserves another. Lvluo village has "meat" every month which 
is the village collectively pay, and buy a pig, hire a few butcher to cook, and the village per capita can take pot or bowl on the platform. All households shares the pork so that the villagers can eat meat at least once per month. The tradition still continues by every generation. Some people of the village who are lonely or mental disorders, the villagers will bring their meal to them, occasionally even will directly give money. All in all, the Lvluo villagers under the decentralized of religious belief of benign makes them in the same boat, making village develop better.

\section{The Mechanism of the Formation of the Collective Action by the Dispersed Religion and the Management Style}

Olson, in his book "the logic of collective action" argues that the formation of the collective action is result of the existence of "free-rider" phenomenon, people always want to pay a minimum cost to obtain the interests of the collective, and creates a collective action, at the same time, he thought the little collective is more superiority than the big collective, and will be better in providing public goods and services. Using this theory can yet be regarded as a kind of new public management paradigm to analyze the clan as the link of the dispersion of religion for the generation of the rural collective action and management of rural grassroots autonomy.

First, it is the common blood ties. Due to the migration mechanism of small-scale peasant society in ancient China is not advanced, so contributed to the fellow villagers in village more or less a certain blood relationship, they have a common ancestor, and development to the modern society, the same ancestor and the same faith evolved into a mature of the dispersion of religion, that's what provide a objective basis for the development of collective action, the human society has become a starting point of the collective action.

Organizations at the grass-roots level can repair the family genealogy and hold sire bond activities by calling for the villagers, conduct RenZuGuiZong activities. First this is not only deepened the connection between the consanguinity kin, but also made a possibility to the birth of collective behavior, it is more advantageous to the villagers "do things" together and strengthen the cohesion between the village of the villagers to collective interests for the sake of maximizing. Second it can find the villagers that already move out by repairing genealogy, Chinese people pay attention to falling leaves and return home, the villagers already moved out also can produce feedback if they have a good development in outside, they can create new development opportunities for the local rural. The combination of grassroots governance and "acquaintance society" ethic relationship will get twice the result with half the effort in governance effect.

The second is the same customs and geography. The same customs and geopolitical created a common social situation and make social situation as the decisive factor of social consciousness, and also provide motives for expansion of collective action. The same customs and geopolitical respectively create a small community in the subjective and objective, and in this community, people have same demands, and a similar custom is the embodiment of the dispersion of religious.

Rural organizations at the grass-roots level can hold lions section, provide a forum for the village activities or staff, so far as to make village customs feature into a brand, through carrying out the agricola, attracting tourists to let folk to bring economic income to the villagers. Whereby rural grassroots autonomous organizations bringing belief customs of villagers' in order and systematism due to the dispersion of religious, both make the villagers cultural activities richer, and to strengthen the cohesion of the people in our village, and with the aid of the external force to realize the new rural development.

The third is the common interest orientation. Although different individuals have different interests, once the groups' common interests exist, their action will begin to merge. Under the leadership of the political elite, the decentralized religion will be used by individuals to seek the interests of cooperation partners to provide a convenience, so they began sharing a common behavior. At the same time, they make efforts in order to achieve collective activities, moreover give up some personal interests in order to achieve greater collective goals, to attain their common interests.

Grassroots autonomous organizations should make full use of its own political authority, called 
the villagers, with a common expression of demand, so that make the villagers have common interests, to achieve collective action, better provision of public goods in rural areas. For example, the above traffic inconvenience, affected villagers' travel, the village meeting publicity led the villagers to donate money in which improve the road infrastructure the construction of rural villagers. When there are many scattered individual interests, such as some villagers occupied a good place, then others will react, even in the dark at the formation of internal contradictions, strike violently, is not conducive to the stable development of rural grassroots. Organizations can play a normative role. for example, the use of regulations of the land use rights. Make clear regulations, and impose a warning on who are in violation of regulations.

As a kind of spiritual culture, the decentralized religion affects the villagers'rural grassroot self-govern. Grassroot self-government can combine the decentralized religious with grassroots governance together, for the better ways to provide public goods in rural areas, push rural economic development, maintaining social stability in rural areas, to rich the villagers spiritual and cultural life, better constructed the socialist new countryside.

\section{Reference}

[1] Zhang Wenjie: the attemptment to comment on the study of Chinese Religion in "Political economy" in, society of China's religion, March 2014, thirty-fourth volumes.

[2] Zheng Xiaoliang: A review of current research on rural religious issues, Journal of Hubei University of Economics (HUMANITIES AND SOCIAL SCIENCES), second volume seventh, July 2005.

[3] Li Peng: The transformation of social people's religious belief and guidance -- Taking Shanxi as an example, Huazhong Normal University Xiaxian. 